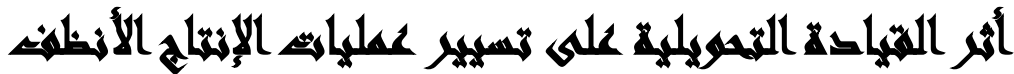

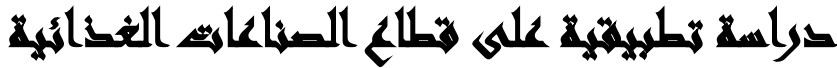

\section{$[r Y]$}

بثينة محمد عبد الحميد(')- ممدوح عبد العزيز رفاعي(())- محمد عبد الرازق النواوى(")

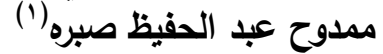

() المعهد العالي لعلوم الكمبيوتز وتكنولوجيا الإدارة، سوهاج r r) كلية التجارة، جامعة عين

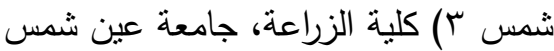

\section{المستيلتى}

يهدف هذا البحث إلى اختبار مدى وجود علاقة بين القيادة التحويلية وعمليات الإنتاج الأنظف، والتعرف على أثز أبعاد القيادة التحويلية على تسيير عمليات الإنتاج الأنظف الإنف

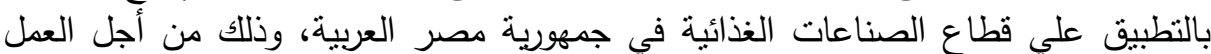

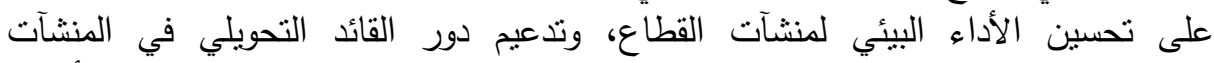

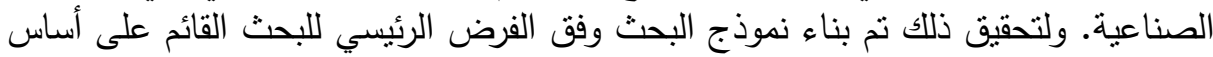

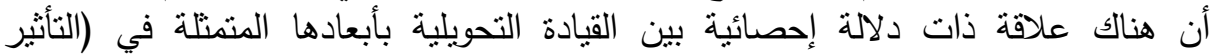

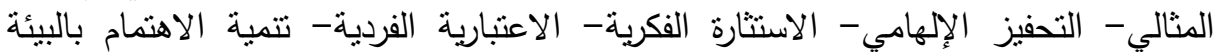

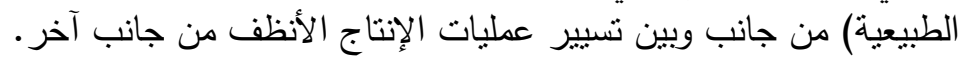

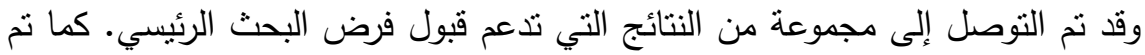
التوصل إلى مجموعة من التوصيات التي من شأنها أن تساعد في تحسين أداء التهاد القادة داخل

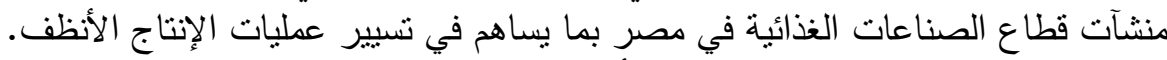

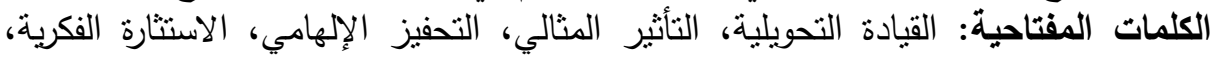
الاعتبارية الفردية، الإنتاج الأنظف. اللفادهات

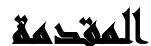

يتسم هذا العصر بأنه عصر اختصار الزمن وتقريب المكان، والتغيرات المتلاحقة في

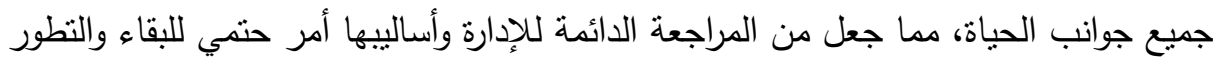
ومواكبة التغير من حولنا (معيقل، 10 بـ). ولكي تضمن المنظمات تحقيق أهدافها بكفاءة وفاعلية لمواجهة التحديات المستقلية والمتغيرات العالمية يجب توافر قيادات إدارية فاعلة قادرة

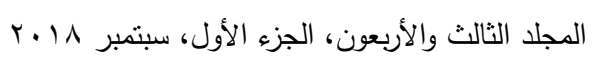


على وضع رؤية واضحة لمنظماتها، التي من شأنها العمل على إيجاد نظم وتوجهات جديدة

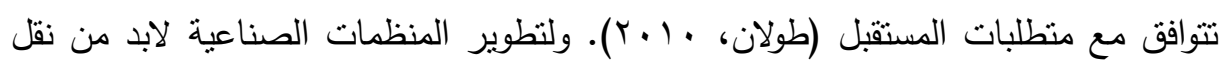
وتوطين التكنولوجيا الحديثة في مجال تطوير العمليات الإنتاجية وتحسين كفاءة استخدام

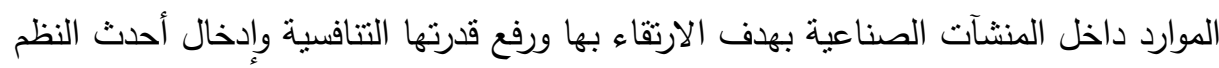
التكنولوجية في العمليات الإنتاجية وكذلك تطبيق نظم ترشيد الموارد من طاقة ومياه ومواد خام والتوافق مع المنطلبات البيئية في الصناعات المصرية (SWITCH-MED program)

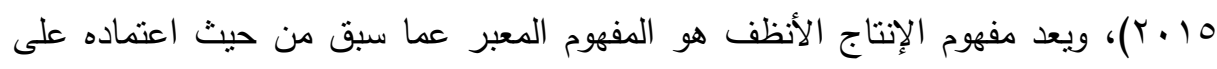

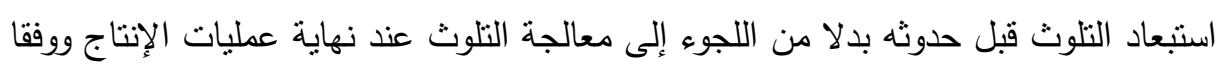
لتعريف برنامج الأمم المتحدة للبيئة يعتبر الإنتاج الأنظف نطبيق مستمر لإستراتيجية منكاملة

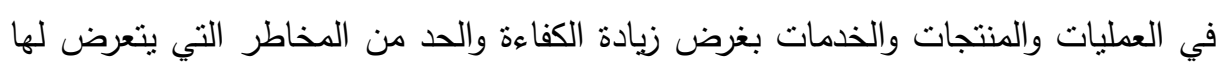
الإنسان والبيئة.

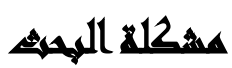

بالرجوع للاراسات والبحوث في هذا المجال تبين وجود دراسات عديدة تتاولت القيادة

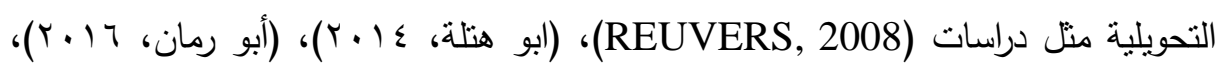

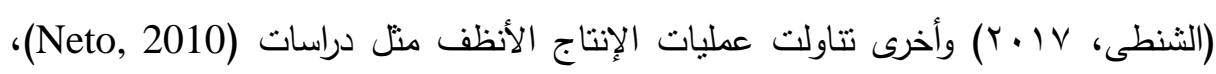

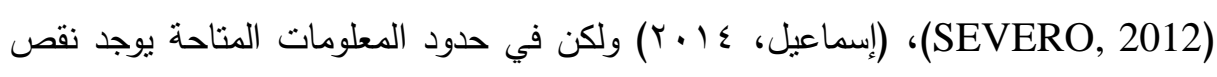
شديد إن لم يكن ندرة في البحوث والدراسات التي ربطت بين القيادة التحويلية كأحد أنماط القيادة وبين عمليات الإنتاج الأنظف، ونظراً لصعوبة الحصول على ولى بيانات تتعلق بمجال

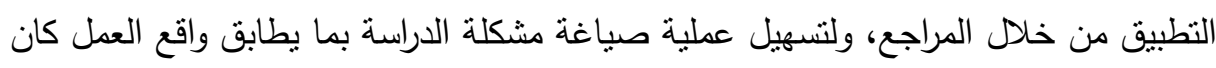
من الضروري إجراء دراسة استطلاعية في قطاع الصناعات الغذائية لاستكمال البيانات الخاصة بموضوع البحث وإمكانية صياغة المشكلة، حيث تم تصميم قائمة استقصاء واستطلاع رأى مفردات العينة عليها. وقد أظهرت نتائج استطلاع الرأي أن قبول العاملين للتغيير في تكنولوجيا الإنتاج يرجع إلي إقناع القائد لهم بقبول ذلك التغيير، كما أن صفات التأثثر المثالي والاعتبارية الفردية في لئي 
مجلة العلوم البيئية

معهد الدراسات والبحوث البيئية - جامعة عين شمس لئ

القائد التحويلي هي الأكثر تأثثرا في العاملين من وجهة نظر مفردات العينة الاستطلاعية، وبناء على ذلك تم وضع أسئلة البحث.

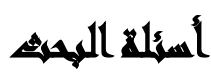

يتمثل التساؤل الرئيسي للبحث في "ما مدى وجود علاقة بين القيادة التحويلية وتسبير

$$
\text { عمليات الإنتاج الأنظف؟ }
$$

وينبثق من التساؤل الرئيسي التساؤلات الفرعية التالية:

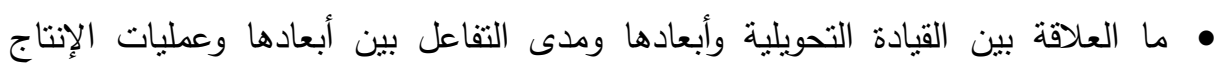
الأنظف؟ مأ العله

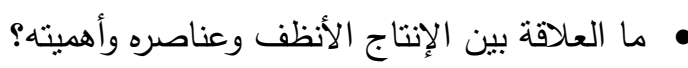

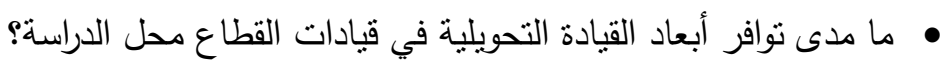

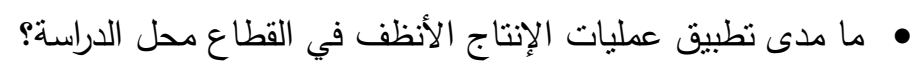

\section{أهساهـ المهثي}

ه التعرف علي مدي وجود ارتباط بين القيادة التحويلية وتسيير عمليات الإنتاج الأنظف في القطاع محل الدراسة. هراسة القيادة التحويلية وأبعادها ودراسة الإنتاج الأنظف واستتناج مدى التفاعل بين أبعاد

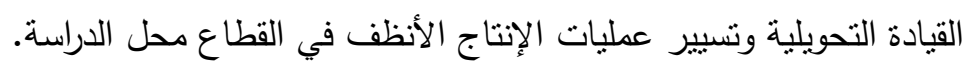

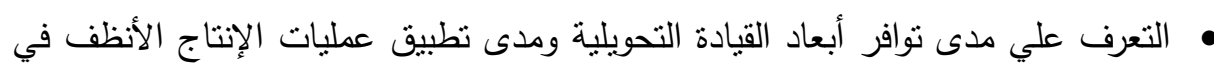
القطاع محل الدراسة. • تقديم مجموعة من المقترحات والتوصيات التي يمكن أن تقيد مجال الدراسة. 


\section{هروخ المهنه}

الفرض الرئيسي: "توجد علاقة ذات دلالة إحصائية بين القيادة التحويلية بأبعادها وتنيير

$$
\text { عمليات الإنتاج الأنظف". }
$$

وينبثق عنه الفروض الفرعية التالية:

• توجد علاقة ذات دلالة إحصائية بين الكاريزما كأحد أبعاد القيادة التحويلية وتسيير عمليات

$$
\text { الإنتاج الأنظف. }
$$

• توجد علاقة ذات دلالة إحصائية بين الاستثارة الفكرية كأحد أبعاد القيادة التحويلية وتسيير

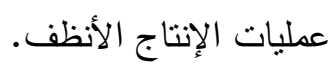

• توجد علاقة ذات دلالة إحصائية بين التحفيز الإلهامي كأحد أبعاد القيادة التحويلية وتسيير

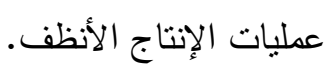

• توجد علاقة ذات دلالة إحصائية بين الاعتبارية الفردية كأحد أبعاد القيادة التحويلية وتسيير

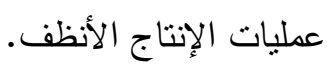

• توجد علاقة ذات دلالة إحصائية بين تتمية الاهتمام بالبيئة كأحد أبعاد القيادة التحويلية

$$
\text { وتنيير عمليات الإنتاج الأنظف. توجد دله داته }
$$

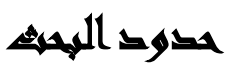

الحدود الزمنية: تم إجراء الدراسة خلال الفترة من ^ ... حتى تاريخ تجميع البيانات

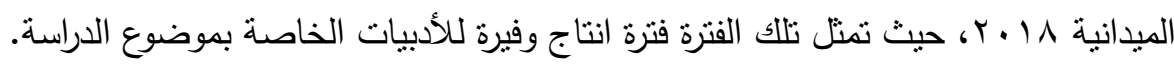
الحدود المكانية: اقتصر البحث علي قطاع الصناعات الغذائية بجمهورية مصر العربية (قطاع الصعيد بشكل خاص) نظرًا لأهمية القطاع في مجال الصناعة والتجارة في مصر .

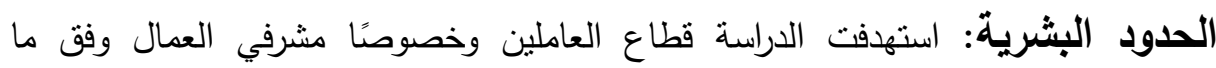
توصلت إلية الدراسة من أراء العينة القبلية. الحدود الموضوعية: اقتصرث الدراسة علي البحث في القيادة التحويلية وأبعادها كمتغير مستقل، والإنتاج الأنظف بجميع أبعادة كمتغير تابع. 


\section{هنهمج المهيد}

تحقيقا لأهداف البحث واختبار فروض البحث نم تقسيم منهج البحث كالتالى: الاراسة النظرية: نعتمد علي المنهج الوصفي التحلبلي من خلال سرد للأدبيات المنعلقة بمتغيرات الدراسة وتكوين إطار نظري من مصادر عديدة (الكتب والدوريات العربية والأجنبية، الرسائل العلمية المنشورة وغير المنشورة، شبكة المعلومات القومية، التقارير الصادرة عن المؤتمرات، التقارير الصادرة عن الجهات ذات الصلة بموضوع الدراسة، الدراسة الاستطلاعية

أو الاستكثافية).

الاراسة الميأية: من خلا تصميم قائمة الاستقصاء وتوجيهها لمفردات عينة الدراسة واستنفاء هذه القوائم وتحليلها حتى الوصول للنتائج والتوصيات.

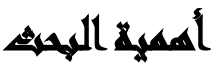

الأهمية النظرية: تتضح أهمية البحث من خلال تتاوله لمتغيرين في غاية الأهية للمنظمات الصناعية والاقتصادية وهما القيادة التحويلية بأبعادها الخمسة ( الكاريزما، التحفيز الإلهامي، النظرة الفردية، الاستثارة الفكرية، تتمية الاهتمام بالبيئة الطبيعية) وعمليات الإنتاج الأنظف حيث يوجد هناك نقص في الدراسات السابقة وخاصة العربية التي تتتاول مفهوم القيادة التحويلية وربطة بالإنتاج الأنظف، وإجراء هذا البحث يعد مساهمة في حقل المعرفة الاجتماعية والإدارية والبيئية حيث يلقي الضوء علي أهمية دور القيادة التحويلية في تسيير عمليات الإنتاج الأنظف. الأهمية التطبيقية: تأتي أهمية التطبيق على القطاع محل الدراسة لما سوف تنثله نتائج البحث من وسيلة لمساعدة المنظمات الصناعية على معرفة مدى قدرة القيادة بشكل عام

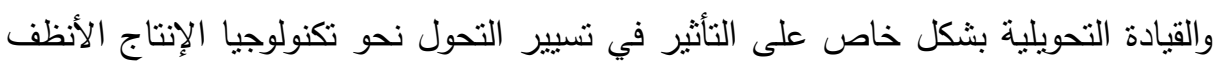




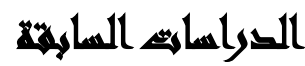

من خلال سرد الأدبيات المتعلقة بمتغيرات الدراسة تم استعراض أهم الدراسات السابقة، وتم تقسيمها إلى دراسات متعلقة بالمتغير المستقل (القيادة التحويلية)، ودراسات متعلقة

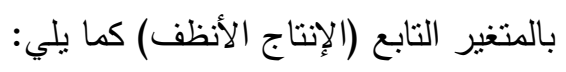
دراسات متعلقة بالقيادة التحويلية:

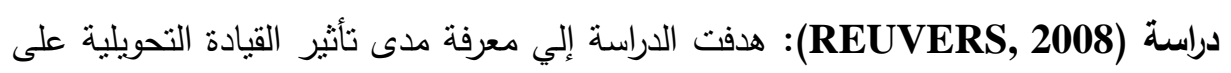

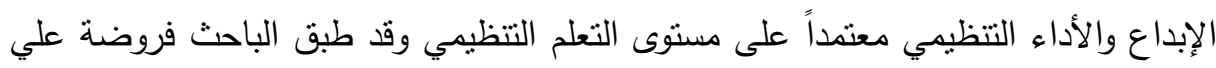

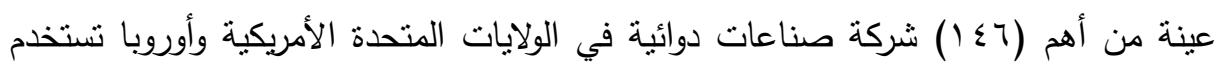
تكنولوجيا متقدمة.

وكان أهم نتائجها وجود علاقة ارتباط قوية بين القيادة التحويلية والأداء التتظيمي بالإضافة إلى أن هذه العلاقة تكون أقوى في الثركات التي تتميز بتعليم تتظيمي مرتفع مقارنة بنلاك التي لديها تعليم تتظيمي اقل. دراسة أبو هتلة (ـ ا ـ ץ): هدفت الدراسة إلى التعرف على مدى انسجام القيادة التحويلية مع

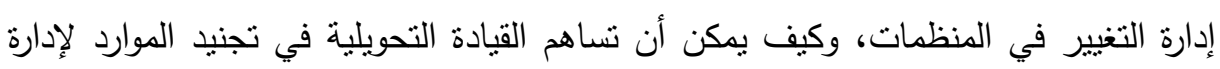
التغيير وتوصلت الدراسة إلى أن القيادة التحويلية هي القيادة الملائمة لعملية التغيير ، كما تتفوق

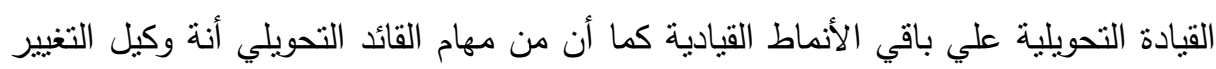

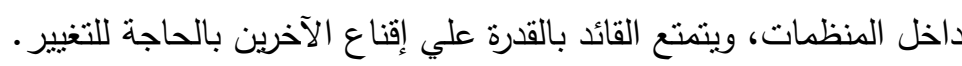

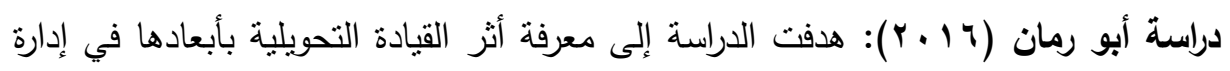
الأزمات. وتوصلت الدراسة إلى أكثر أبعاد القيادة التحويلية تأثثر في الاستعداد لإدارة الأزمات هو بعد التمكين يليه الاعتبارية الفردية ثم الاستثارة الفكرية.

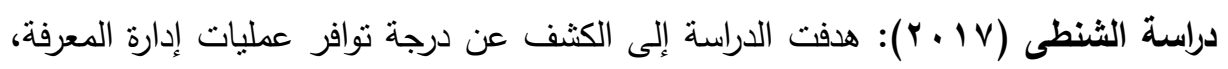

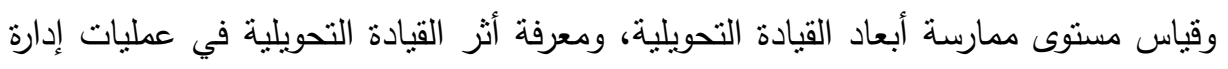
المعرفة. 
وتوصلت الى إلى أن مستوى ممارسة أسلوب القيادة التحويلية وممارسة إدارة المعرفة كان متوسط، كما يوجد أثر ذو دلالة إحصائية للقيادة التحويلية (باستثاء بعد الدافع الإلهامي) في عمليات إدارة المعرفة. دراسات متعلقة بالإنتاج الأنظف: دراسة (Neto, 2010): هدفت الدراسة إلى اقتراح بعض التوجهات لاعتماد تطبيق تكنولوجيا

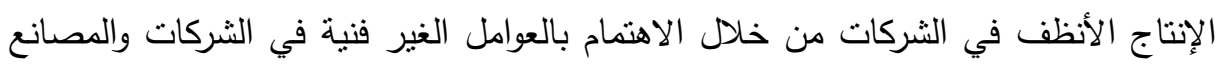
(والمقصود هنا الموارد البشرية والثقافية والتتظيمية والتدريب).

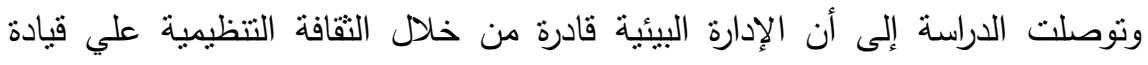

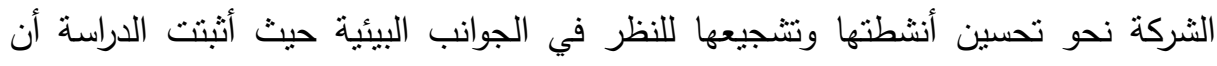
التفاعل بين إدارة الموارد البشرية والجوانب البيئية يفتقر لحسن الإدارة النظرية والتجريبية وهذه

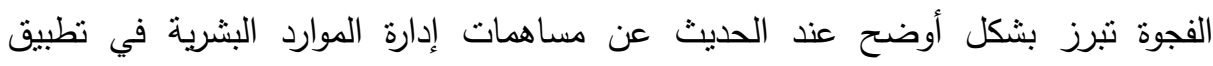
تكنولوجيا الإنتاج الأنظف لذا يوصي الباحثون بالاهتمام في الدراسات المستقبلية بمدى تأثنير

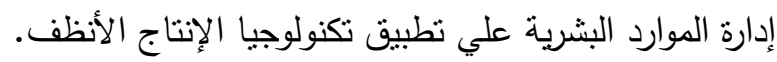
دراسة (SEVERO, 2012): هدفت الدراسة إلي تحديد الابتكارات البيئية ومنهجيات الإنتاج الأنظف ونتائج تتفيذها من خلال دراسة حالة علي ثلاث شركات في مجموعة معادن ميكانيكا السيارات بالبرازيل.

وتوصلت الدراسة إلى أن تتفيذ منهجيات الإنتاج الأنظف له تأثير على تحسين العمليات الإنتاجية وخفض التكاليف وتحقيق تسرب أقل للمخلفات.

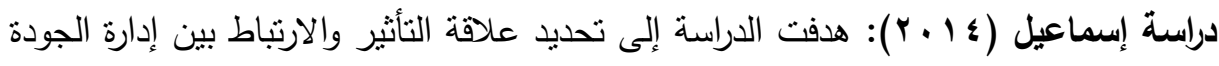
البيئية الثشاملة والممارسات التي تعتمدها الثركة المبحوثة في سعيها نحو الحفاظ على الموارد الأولية والمياه والطاقة والتخلص من المواد السامة. وتوصلت الدراسة إلى وجود علاقة ارتباط معنوية بين عناصر إدارة الجودة البيئية

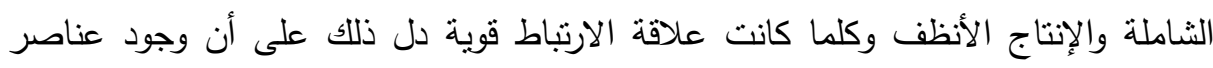


إدارة الجودة البيئية الثناملة ينعكس على تعزيز ممارسات تكنولوجيا الإنتاج الأنظف المتمنلة

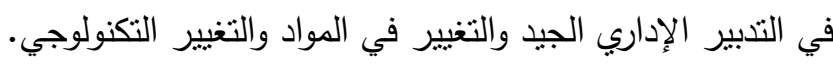
دراسة (Sakr, 2017): هدفت الدراسة إلى تقييم اعتماد الإنتاج الأنظف على أساس إطار

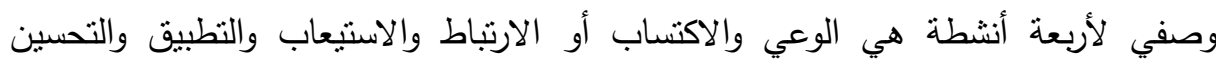
المستمر للشركات الصناعية المصرية.

وتوصلت الدراسة إلى أن الثركات الصناعية التي شملتها الدراسة في مرحلة مبكرة من

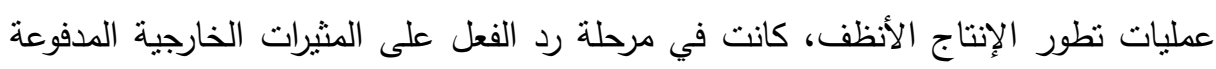
من قبل الحكومة والبرامج الدولية التي ترعاها الجهات المانحة خلال العشرين عاما الماضية.

\section{الإطال المعرهيهي}

مفهوم القيادة التحويلية: رأى Burns بأن القيادة التحويلية هي عمليه تحفز المرؤوسين وتساعدهم في ابتكار الحلول وبذلك تحل محل القيادة التقليدية التي تعتمد على تبادل المصالح

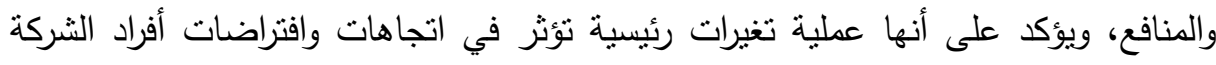
وبناء الإلتزام نحو أهداف الثركة وإستراتيجيتها ورسالتها (Burns, 1978)، وقد استتد كثير

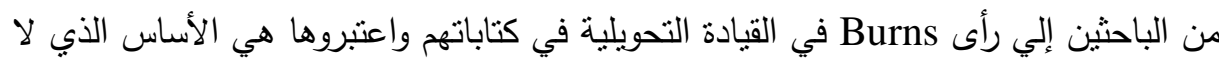

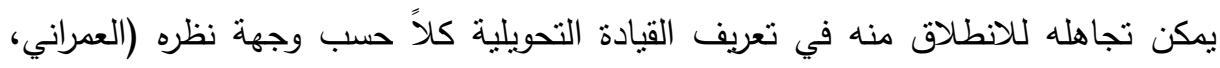

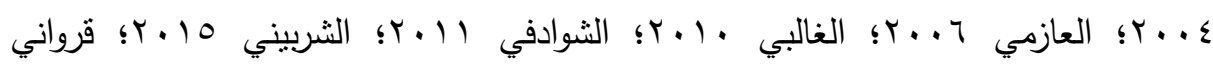

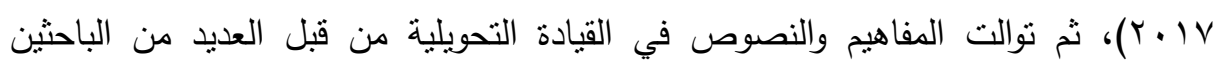
والعلماء.

التأثير المثالي: أحد أبعاد القيادة التحويلية، وهو ممارسة القائد لسلوك يجعل منه نموذج يجب أبلاء

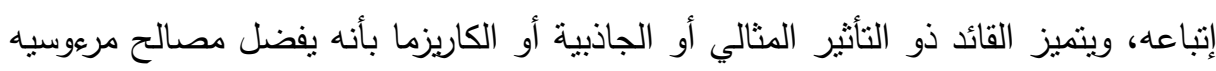

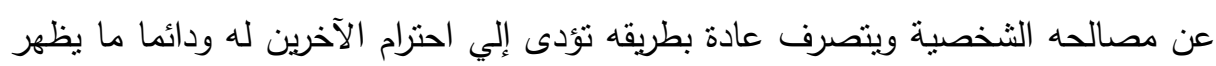

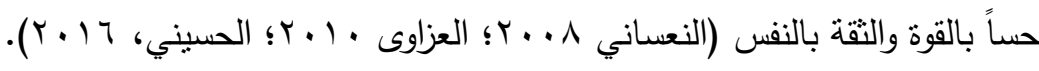

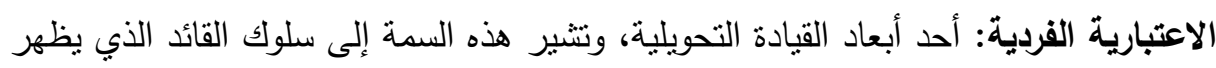
الاهتمام والرعاية لأتباعه، ويعمل على تحقيق الارتياح والرفاهية الدائمة لهم وأن يكون موجهاً

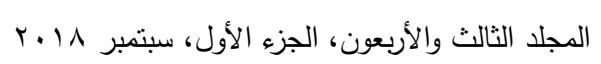


لأعضاء الفريق (Ismail, 2010)، كما أنه يساعد كلًا منهم في الحصول علي ما يريد،

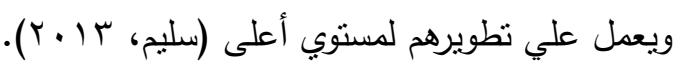
الاستثارة الفكرية: أحد أبعاد القيادة التحويلية وهي تعني سلوك القئي القيائد في البحث عن أفكار

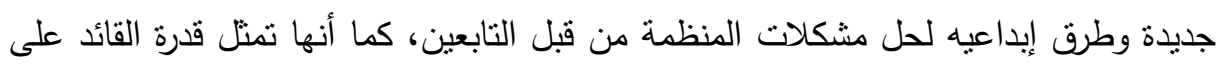

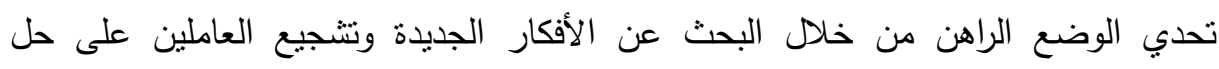
المشاكل بأساليب مبتكره (Twigg, 2003 ; Al-Swidi, 2012)، ودعم النماذج الجديدة في طرق العمل، مما يولد نوع من الثقة الفطرية في تطوير العاملين كونها نرتبط إيجابيًا مع مواقف القاده (الساعاتي، 0 1 • ب). التحفيز الإلهامي: أحد أبعاد القيادة التحويلية وهو تصرفات القائد التي تثير في التابعين

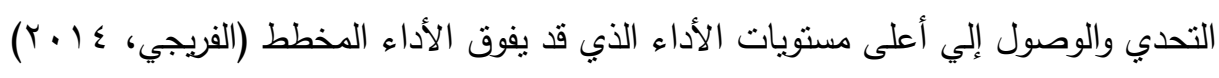

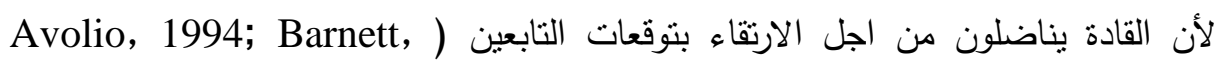

تنمية الاهتمام بالبيئة الطبيعية: أحد أبعاد القيادة التحويلية حيث أنها تعني السلوكيات

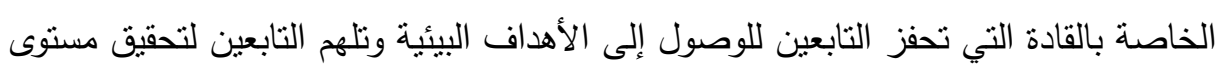

أداء بيئي يتجاوز المسنوي المنوقع (Chen, 2013). مفهوم الإنتاج الأنظف: يهدف مفهوم الإنتاج الأنظف بشكل أساسي إلى معالجة المشاكل

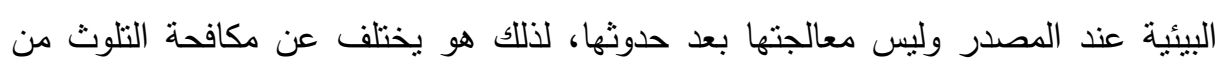
حيث التوقيت لأن المكافحة تأتي بعد حدوث المشكلة، في حين أن الإنتاج الأنظف يمنع لئن

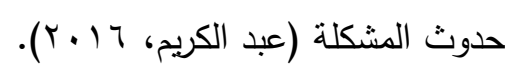

\section{اجباعاهث المهيد}

متغيرات الدراسة وأسلوب قياسها: من خلال الدراسات السابقة والدراسة الاستطلاعية نم تحديد المتغيرات المستقلة والتابعة في الدراسة الحالية ، ويمكن وضع المتغيرات في النموذج التالي:

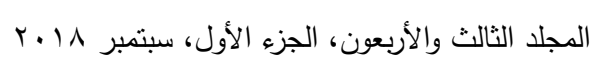




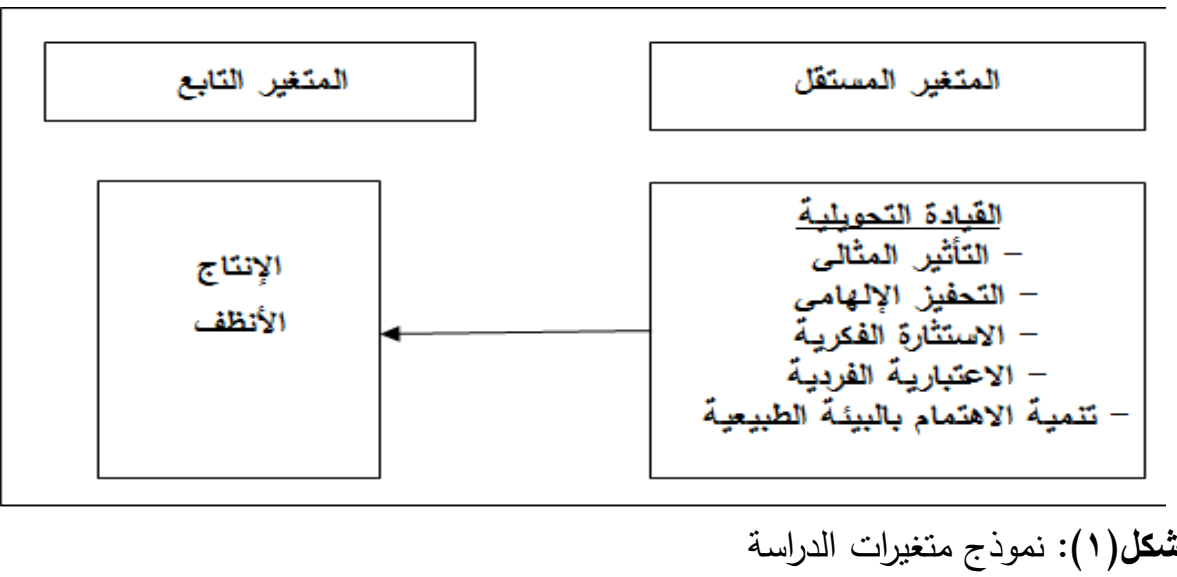

المتغير المستقل: القيادة التحويلية هي المتغير المستقل الوحيد، ويتكون من خمسة أبعاد

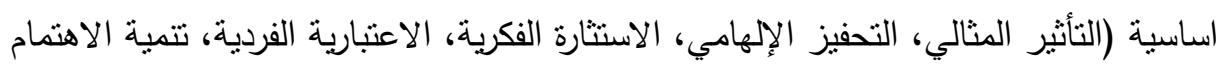

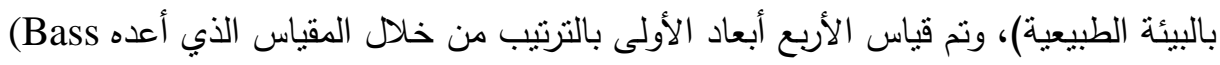

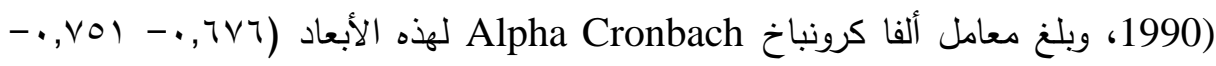

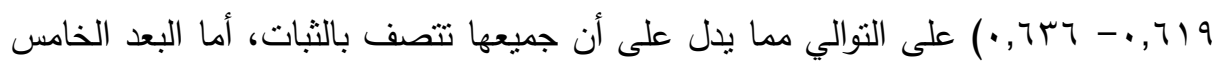
فقد تم قياسه من خلال مجموعة من العبارات تمت صباغتها وفق الأدبيات العربية والأجنبية

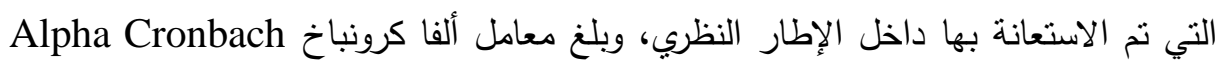

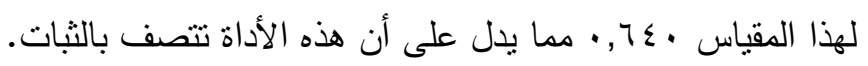

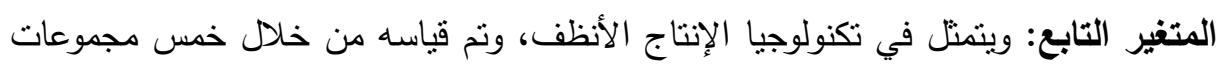

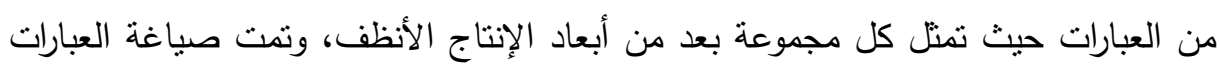

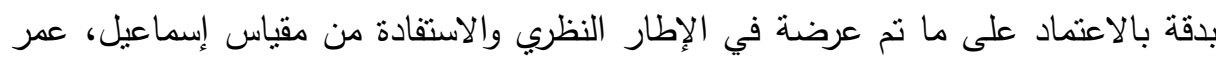

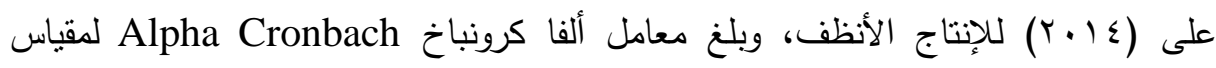

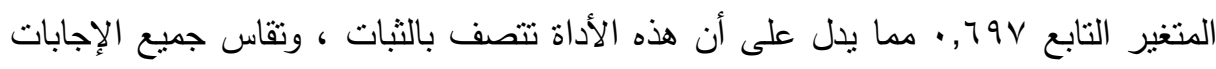
على مقياس ليكرت خماسي الدرجات. مجتمع وعينة الاراسة: يتمثل مجتمع الدراسة في جميع منشآت الصناعات الغذائية التي لني تطبق عمليات الإنتاج الأنظف داخل جمهورية مصر العربية البالغ عددها . . بـع منشأة تتضمن ·ـ ـ منشأة تطبق تكنولوجيا الإنتاج الأنظف بعدد عاملين يصل إلى . . 770 عامل، 600

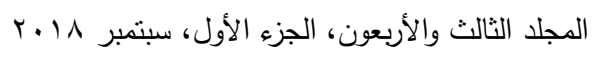


كما بلغ حجم عينة الدراسة ع ب مفردة، حيث حددت مستوى ثقة 90\% ومقدار الخطأ المسموح به عند التقدير ه\%، وقد بلغت استجابة مفردات العينة rجب مفردة أي أنها تعادل \% من حجم العينة.

اختبار أدوات الدراسة: نم اختبار أدوات الدراسة بقياس صدق وثبات مقياس الدراسة على

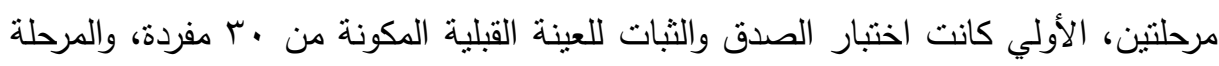
الثانية كانت لجميع مفردات العينة بعد تعديل قائمة الاستقصاء بما تم التوصل إليه من نتائج

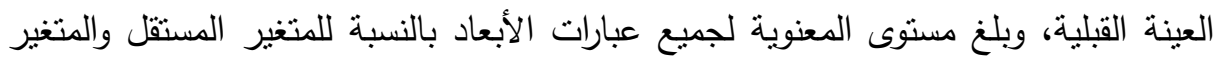

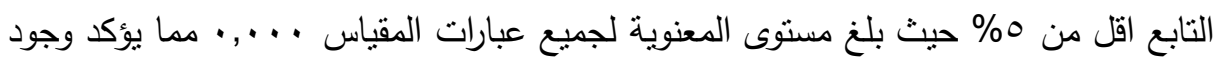
اتساق داخلي بين جميع عبارات الدراسة ، وهو ما يعني صلاحيتها للتحليل الإحصائي. التحليل الإحصائي للبيانات: تم استخدام البرنامج الإحصائي SPSS.vr 25 في تحليل البيانات والتي تم جمعها عن طريق قوائم الاستقصاء ومن أهم المقاييس المستخدمة في لإني التحليل الإحصائي (التحليل الوصفي Descriptive Analysis، اختبار ت لعينه واحدة Chi Square One Samples T-Test

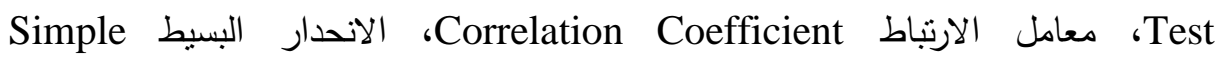
Regression

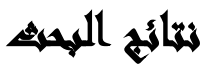

أولاً: العلاقة بين القيادة التحويلية بابعادها وتسيير عمليات الإنتاج الأنظف:

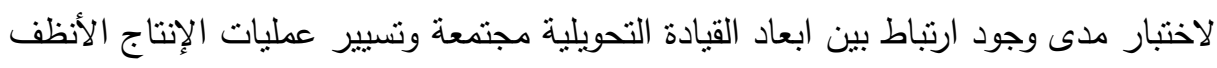
تم استخدام تحليل الارتباط Correlation Analysis كما يوضح الجدول التالي: 
جدول( (1): الارتباط بين أبعاد القيادة التحويلية والإنتاج الأنظف

\begin{tabular}{|c|c|c|c|c|c|c|}
\hline |تنمية الاهتمام & الفردية(X4) الاعبارية & الفكرية(X3) الاستثارة & الإلهامي(X2) & المثالي(X1) & $\begin{array}{l}\text { الأإنتاجف } \\
\text { الأنظا } \\
(Y) \\
\end{array}$ & \\
\hline & & & & & 1 & $\begin{array}{l}\text { الإنتاج الأنظف } \\
\text { (Y) }\end{array}$ \\
\hline & & & & 1 & $* *, 9 \leqslant r$ & $\begin{array}{c}\text { التأثير المثالي } \\
\text { (X1) }\end{array}$ \\
\hline & & & 1 & $* *, 9 \vee V$ & $* *, 9 \uparrow 4$ & التحفيز الإلهامي. \\
\hline & & 1 & $* *, 97 V$ & $* *, 9 \vee \cdot$ & $* *, 9$ ro $^{2}$ & $\begin{array}{c}\text { الاستثارة الفكرية } \\
\text { (X3) } \\
\end{array}$ \\
\hline & 1 & $* *, 9 \vee 1$ & $* *, 9 \vee 1$ & $* *, 910$ & $* *, 9 Y Y$ & الاعتبارية الفردية \\
\hline 1 & **, • Tro & $* *, r T V$ & ***, & $* *, r)$. & $* *, Y \backslash 7$ & تنمية الاهتمام بالبيئة \\
\hline,,$\ldots$ & $\cdot, \ldots$ & $\cdot, \ldots$ & $\cdot, \ldots$ & $\cdot, \ldots$ & $\cdot, \ldots$ & Sig.(2-tailed) \\
\hline
\end{tabular}

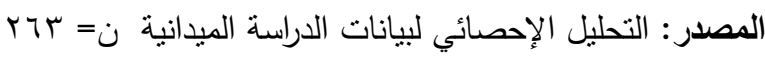

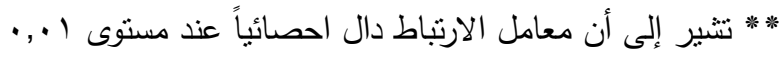

يتضح من مصفوفة الارتباط وجود علاقة ارتباط ذات دلالة معنوية موجبة بين الثأثير

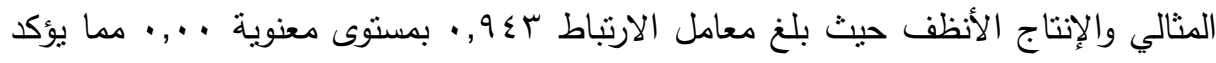

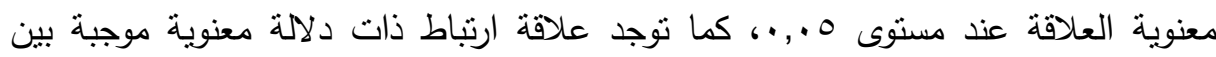

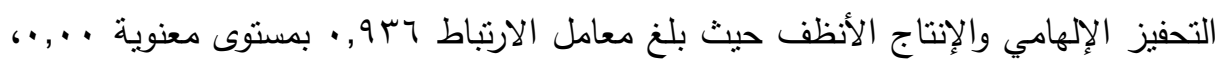

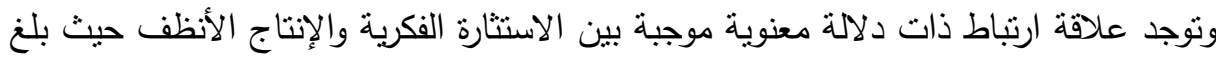

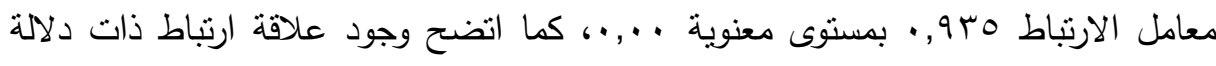

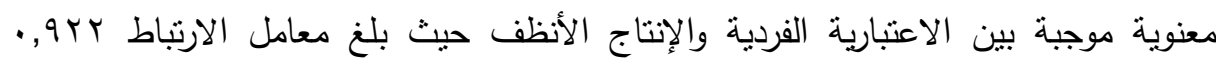
بمستوى معنوية ., .،، كما توجد علاقة ارتباط ذات دلالة معنوية موجبة بين تتمية الاهنمام

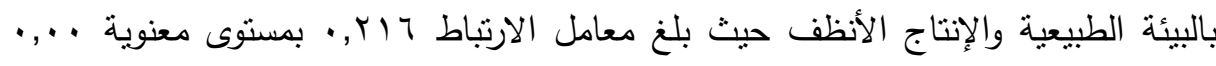

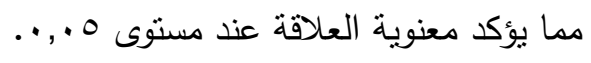


ثانياً: أثز القيادة التحويلية على تسيير عمليات الإنتاج الأنظف: ولاختبار فروض البحث تم قياس تأثثر كل بعد من أبعاد القيادة التحويلية علي تسيير عمليات الإنتاج الأنظف

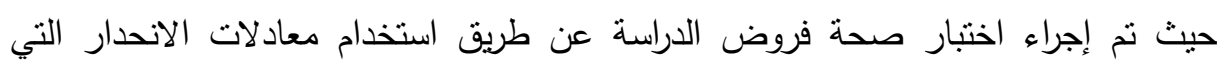
توضح العلاقة بين كل بعد من أبعاد القيادة التحويلية والإنتاج الأنظف كالتالي: الفرض الفرعي الأول: يهدف هذا الفرض إلى اختبار طبيعة العلاقة بين التأثير المثالي كأحد

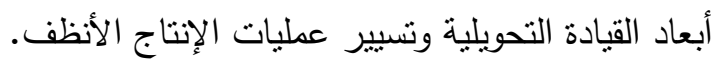
جدول(ץ): تحليل الانحدر لتسيير عمليات الإنتاج الانظف كمتغير تابع، مع التأثثر المثالي كمتغير مستقل

\begin{tabular}{|c|c|c|c|c|c|c|c|}
\hline Sig. T & Sig. F & الثابت & Adj. $R^{2}$ & $\mathbf{R}^{2}$ & $\mathbf{R}$ & Beta & المتغير \\
\hline$\cdot, \ldots$ & $\cdot, \cdots$ & $\{0, \varepsilon)$. & $\cdot, \wedge \wedge q$ & $\cdot, \wedge 9$. & -, $9 \leqslant r$ & $1, \wedge \wedge V$ & التأثير المثالى \\
\hline
\end{tabular}
يلاحظ من الجدول السابق وجود علاقة نرابط جوهرية بين بعد التأثير المثالي، وتسبير

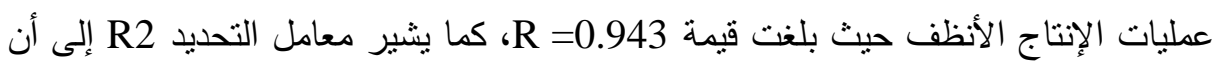

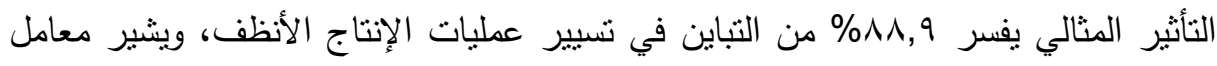

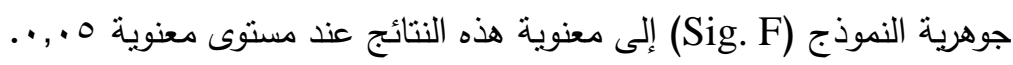
ومن نتائج الجدول السابق يمكن قبول الفرض القائل بوجود علاقة ذات دلالة إحصائية بين المتغير المستقل والمتغير التابع ، كما يوجد تأثير جوهري موجب لبعد التبن التأثير المثالي على

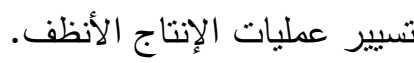
الفرض الفرعي الثاني: يهدف هذا الفرض إلى اختبار طبيعة العلاقة بين الاستثارة الفكرية

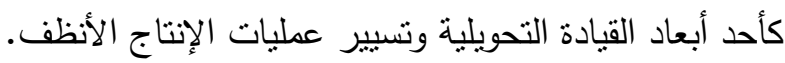
جدول(ץ): تحليل الانحدر لتسيير عمليات الإنتاج الانظف كمتغير تابع، مع الاستتارة الفكرية كمتغير مستقل

\begin{tabular}{|c|c|c|c|c|c|c|c|}
\hline Sig. $T$ & Sig. F & الثابت & Adj. $\mathbf{R}^{2}$ & $\mathbf{R}^{2}$ & $\mathbf{R}$ & Beta & المتغير \\
\hline$\overline{c, \ldots}$ & e, , . & 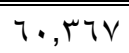 & $=\frac{1, \wedge V V}{}$ & ·, AVV & (.,947 & $r, \wedge \wedge \varepsilon$ & الاستثارة الفكرية \\
\hline
\end{tabular}


يلاحظ من الجدول السابق وجود علاقة ترابط جوهرية بين بعد الاستثارة الفكرية، وتسيير

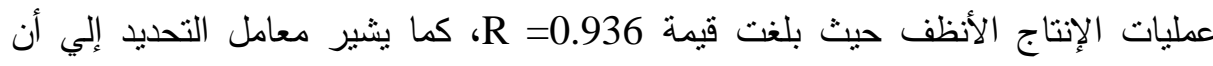

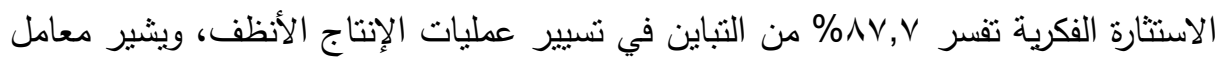

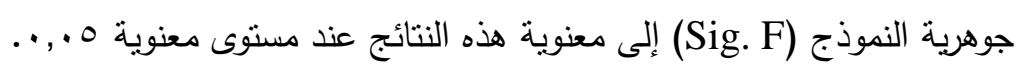

ومن نتائج الجدول السابق يمكن قبول الفرض القائل بوجود علاقة ذات دلالة إحصائية بين المتغير المستقل والمتغير التابع، كما يوجد تأثنر جوهري موجب لبعد البند الاستثارة الفكرية على تسيير عمليات الإنتاج الأنظف.

الفرض الفرعي الثالث: يهدف هذا الفرض إلى اختبار طبيعة العلاقة بين التحفيز الإلهامي كأحد أبعاد القيادة التحويلية وتنبير عمليات الإنتاج الأنظف. جدول(؛ ): تحليل الانحدر لتسيير عمليات الإنتاج الانظف كمتغير تابع، مع التحفيز الإلهامي الإنيات كتغير مستقل

\begin{tabular}{|c|c|c|c|c|c|c|c|}
\hline Sig. T & Sig. F & الثابت & Adj. $R^{2}$ & $\mathbf{R}^{2}$ & $\mathbf{R}$ & Beta & المتغير \\
\hline$\cdot, \ldots$ & $\cdot, \ldots$ & $O V, I A V V$ & $\cdot, \wedge \vee \varepsilon$ & $\cdot, \wedge \vee 0$ & $\cdot, 940$ & $r, 109$ & التحفيز الإلهامي \\
\hline
\end{tabular}
يلاحظ من الجدول السابق وجود علاقة ترابط جوهرية بين بعد الاستثارة الفكرية، وتسيير

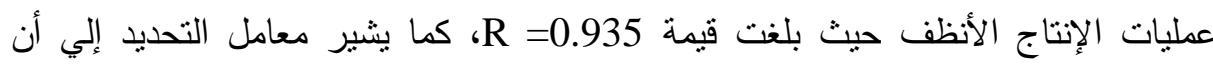

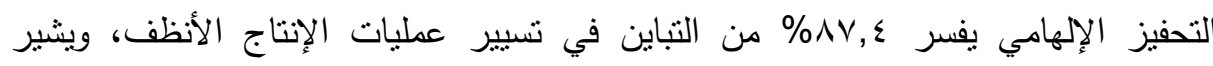

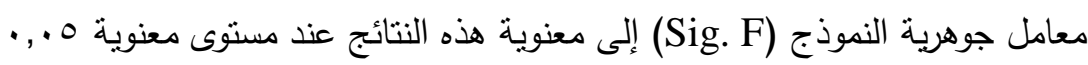

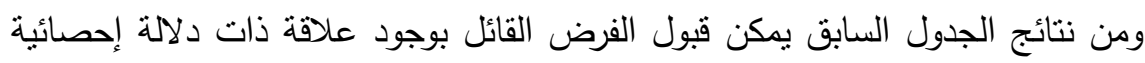
بين المتغير المستقل والمتغير التابع، كما يوجد تأثنير جوهري موجب لبعد التبن التحفيز الإلهامي على تسبير عمليات الإنتاج الأنظف. الفرض الفرعي الرابع: يهدف هذا الفرض إلى اختبار طبيعة العلاقة بين الاعتبارية الفردية كأحد أبعاد القيادة التحويلية وتسيير عمليات الإنتاج الأنظف، ويوضح الجئه الجدول النالي نتائج تحليل الانحدار البسيط. 
جدول(ه): تحليل الانحدر لتسيير عمليات الإنتاج الانظف كمتغير تابع، مع الاعتبارية الفردية كمتغير مستقل

\begin{tabular}{|c|c|c|c|c|c|c|c|}
\hline Sig.T & Sig. F & الثابت & Adj. $\mathbf{R}^{2}$ & $\mathbf{R}^{2}$ & $\mathbf{R}$ & Beta & المتغير \\
\hline$\cdot, \ldots$ & $\cdot, \cdots$ & $07,9 \wedge r$ & $\cdot$, , 0 & $\cdot, 10$. & $\cdot, 9 Y Y$ & r,YYI & الاعتبارية الفردية \\
\hline
\end{tabular}

يلاحظ من الجدول السابق وجود علاقة نرابط جوهرية بين بعد الاعتبارية الفردية،

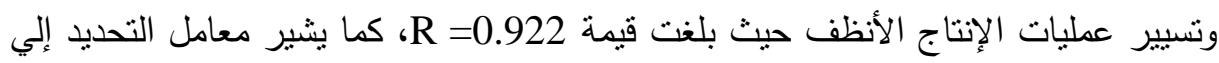

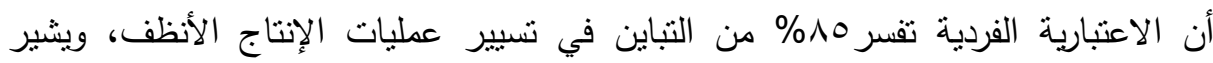

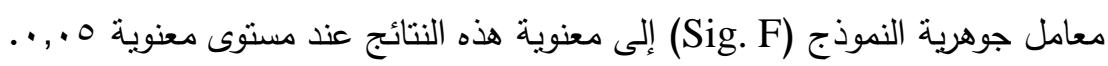
ومن نتائج الجدول السابق يمكن قبول الفرض القائل بوجود علاقة ذات دلالة إحصائية بين المتغير المستقل والمتغير التابع، كما يوجد تأثير جوهري موجب لبعد الاعتبارية الفردية على تسيير عمليات الإنتاج الأنظف. الفرض الفرعي الخامس: يهدف هذا الفرض إلى اختبار طبيعة العلاقة بين تتمية الاهتمام بالبيئة الطبيعية (البعد البيئي) كأحد أبعاد القيادة التحويلية وتسيير عمليات الإنتاج الأنظف. جدول(7): تحليل الانحدر لتسبير عمليات الإنتاج الانظف كمتغير تابع، مع تتمية الاهنمام بالبيئة الطبيعية كمتغير مستقل

\begin{tabular}{|c|c|c|c|c|c|c|c|}
\hline Sig.T & Sig. F & الثابت & Adj. $\mathbf{R}^{2}$ & $\bar{~} \overline{\mathbf{R}^{2}}$ & $\mathbf{R}$ & Beta & المتغير \\
\hline & $\cdot, \cdots$ & $q \pi, \vee \backslash \wedge$ & $\cdot, \cdot \leq \Gamma$ & $\cdot, \cdot \leq V$ & $\cdot, Y \backslash 7$ & $\cdot, \leqslant 01$ & تتمية الالهئة الطسام \\
\hline
\end{tabular}

المصدر: التحليل الإحصائي لبيانات الدراسة الميدانية ن= rجبه

يلاحظ من الجدول السابق وجود علاقة ترابط جوهرية بين بعد تتمية الاهتمام بالبيئة

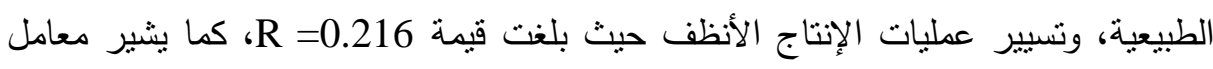

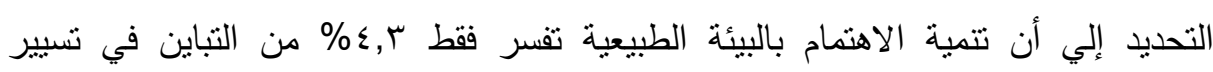

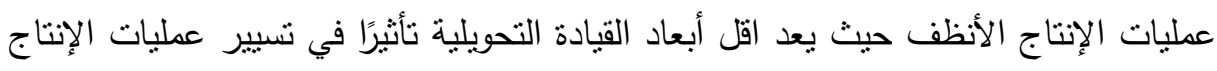
الأنظف، ويشير معامل جوهرية النموذج (Sig. F) إلى معنوية هذه النتائج عند مستوى لئي معنوية 0 ., •. 
ومن نتائج الجدول السابق يمكن قبول الفرض القائل بوجود علاقة ذات دلالة إحصائية بين المتغير المستقل والمتغير التابع، كما يوجد تأثنير جوهري موجب لبعد لبعد تنمية الاهتمام بالبيئة الطبيعية على تسيير عمليات الإنتاج الأنظف. ومما سبق من نتائج الدراسة الميدانية يتضح "وجود علاقية ذالفئ ذات دلاله احصائية بين القيادة التحويلية بابعادها المتمنلة في (التأثير المثالي - التحفيز الإلهامي - الاستثارة الفكرية

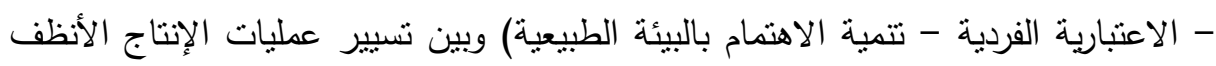

$$
\text { في قطاع الصناعات الغذائية في مصر". }
$$

ثالثاً: الأهمية النسبية للمتغيرات المستقلة في التأثير على المتفير التابع: لمعرفة قوة العلاقة بين ابعاد القيادة التحويلية بشكل كامل، وبين تسيير عمليات الإنتاج

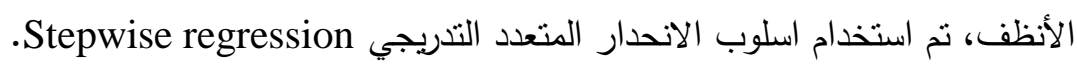
جدول(V): تحليل الانحدار المتعدد التدريجي لبيان تأثثر كل المتغيرات الفرعية على المتغير

\begin{tabular}{|c|c|c|c|c|c|c|c|}
\hline & & & & & \multicolumn{3}{|c|}{ التابع } \\
\hline $\mathbf{F}$ & $\mathbf{T}$ & Adj. $R^{2}$ & $\Delta \mathbf{R}^{2}$ & $\mathbf{R}^{2}$ & $\mathbf{R}$ & Beta & المستقيرة \\
\hline \multirow{5}{*}{ Trr,AV4 } & $0,1 \leqslant 0$ & $\cdot, \wedge \wedge 9$ & --- & $\cdot, \wedge 9$ & $\cdot, 9 \leqslant r$ & $1, \leqslant$ \& & التأثثر المثالي \\
\hline & $r, 1 \cdot \Lambda$ & $\cdot, \wedge 97$ & $\cdot, \cdots v$ & $\cdot, \wedge 9 \vee$ & $\cdot, 9 \leqslant \vee$ & $\cdot, 9 \cdot 7$ & الإلهامفي \\
\hline & $\varepsilon, V \Psi T$ & $\cdot, 9 \cdot \Sigma$ & $\cdot, \cdots \wedge$ & $\cdot, 9 \cdot 0$ & $\cdot, 901$ & $1, \Gamma \wedge 1$ & تتمية الاهتمام \\
\hline & r,vrq & $\cdot, q \cdot V$ & $\cdot, \ldots \varepsilon$ & $\cdot, 9 \cdot 9$ & •,90r & 1,019 & $\begin{array}{c}\text { الاعتبارية } \\
\text { الفردية }\end{array}$ \\
\hline & $\{, 09\}$ & $\cdot, 91$. & $\cdot, \cdots r$ &., $91 Y$ &., 900 &., 19. & لاستثارة الفكرية \\
\hline$\cdot, \ldots$ & $\cdot, \ldots$ & - & - & - & - & - & Sig. \\
\hline
\end{tabular}

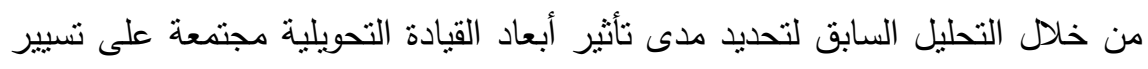

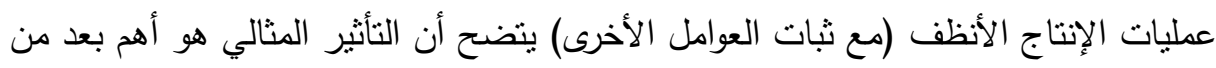

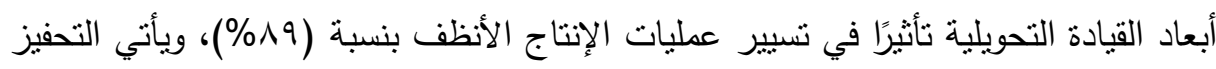

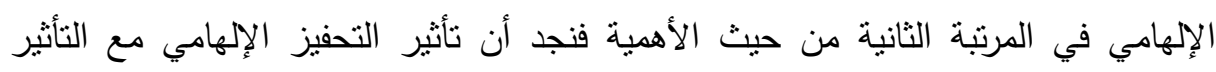
606

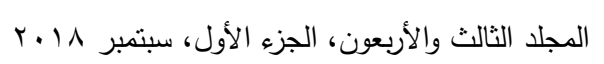




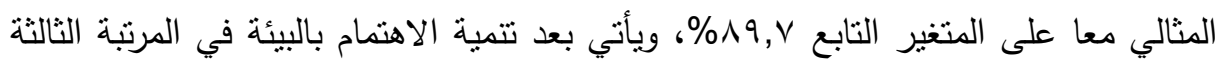

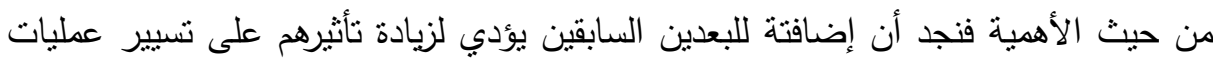

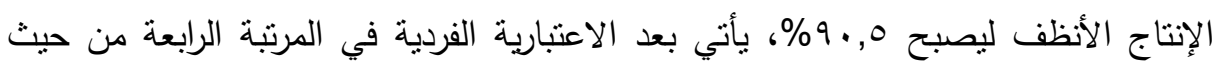

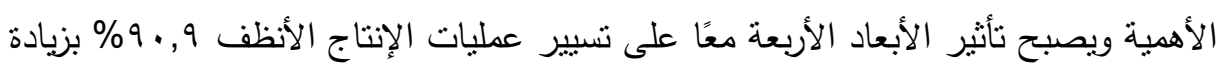

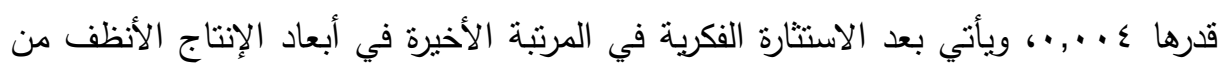

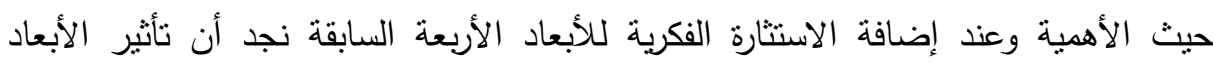

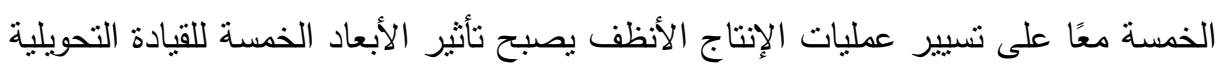

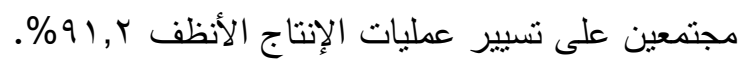

هذه النتائج عند مستوى معنوية قدره ( (., ) حيث كان مستوى المعنوية ( ., • ) لجميع

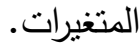

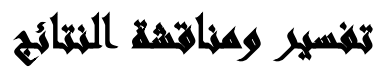

ا. قبول الفرض القائل بأنه توجد علاقة ذات دلالة إحصائية بين القبادة التحويلية بأبعادها وتسبير عمليات الإنتاج الأنظف، حيث ثبت أن هناك تأثير جوهري موجب للقيادة التحويلية بأبعادها على تسيير عمليات الإنتاج الأنظف، وأن هنالك علاقة إرتباط طردي لناني

r. قبول الفروض الفرعية للاراسة والقائلة بأنه نوجد علاقة ذات دلالة إحصائية بين أبعاد

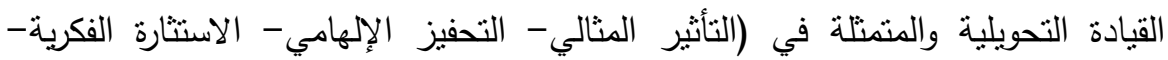
الاعتبارية الفردية- تتمية الاهتمام بالبيئة الطبيعية) وبين تسيير عمليات الإنتاج الأنظف في قطاع الصناعات الغذائية، وكذلك هناك علاقة إرتباط طردية بينهم، فكلما إزداد تأثير المدير في العاملين وتحفيزة لهم، وكلما اهتم المدير بتتمية قدرات مرؤوسية وزيادة وعيهم

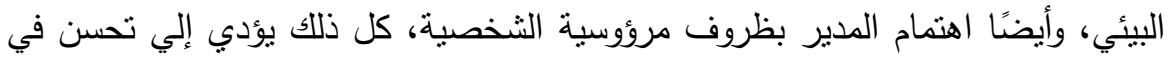

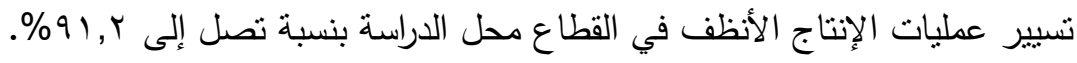
r. جاءت نتائج الفروض الفرعية لنؤكد الفرض الرئيس بشكل كبير حيث جاءت جميعها لتأكيد أن هناك علاقة إرتباط إيجابية في الإتجاه الطردي. 
ع. يمكن ترتيب أبعاد القيادة التحويلية ترتيبًا تتازليا من حيث الأكثر تأثيرًا في تسيير عمليات

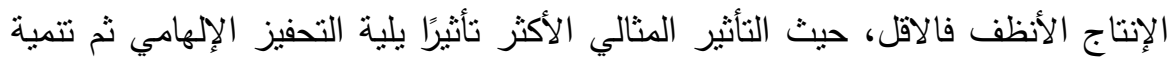
الاهتمام بالبيئة الطبيعية، ويليه الاعتبارية الفردية ليأتي اخيرًا بعد الاستثارة الفكرية.

\section{اللجركياهت}

ا. تتجيع المديرين العاملين داخل قطاع الصناعات الغذائية على ممارسة نمط القيادة التحويلية لما له من تأثير ايجابي علي تحسين سير عمليات الإنتاج الأنظف داخل القطاع، ويأتي ذلك من خلال عمل ندوات ودورات تدريبية من قبل متخصصين في الموارد

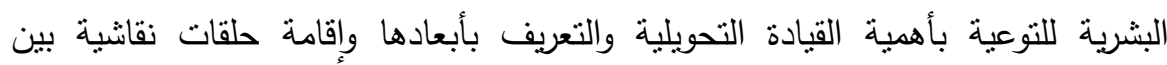

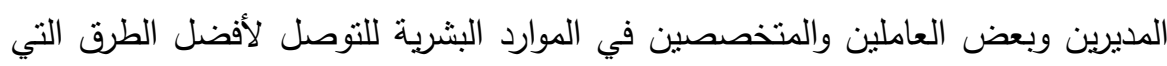
تمكن المنشأة من نشر نمط القيادة التحويلية وتحقيق أقصى استفادة ممكنة.

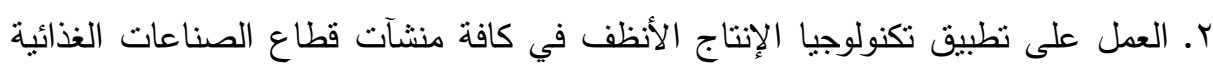

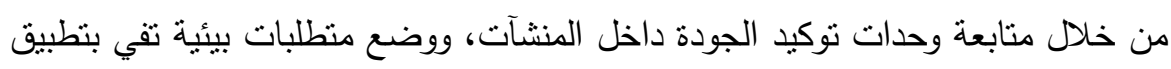
تكنولوجيا الإنتاج الأنظف، كما يجب إلزام المنشآت بوضع علامات علي غلات غلاف المنتج

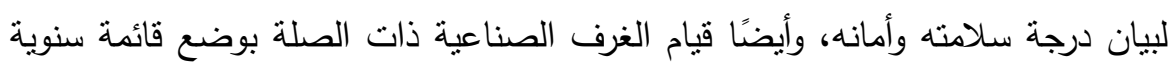

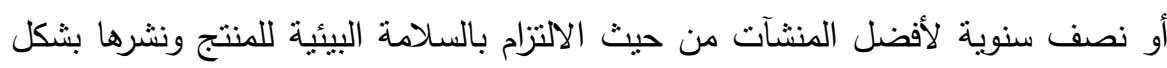

$$
\text { دوري لتعريف المستهلك بها. }
$$

r. تقديم مساعدات للمنشآت الصناعية لتعديل تصميم المنتجات بما يناسب منطلبات الإنتاج

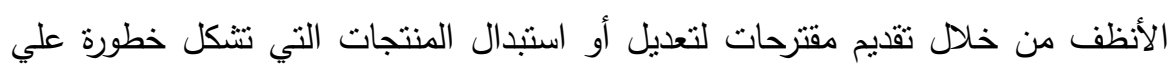

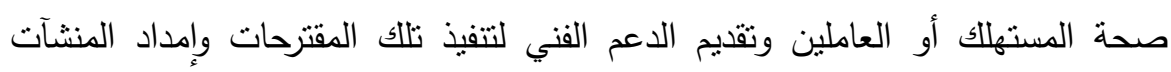
بالتكنولوجيا اللازمة إذا كانت غير متوفرة بالمنشأة.

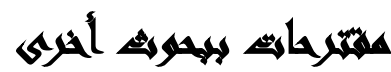

• دراسة أثز القيادة التحويلية علي الإنتاج الأنظف بالتطبيق على قطاعات صناعية غير الصناعات الغذائية (منل الصناعات المعدنية، الصناعات التحويلية). 
التركيز على دراسة مدى توافر بعد تتمية الاهتمام بالبيئة الطبيعية ضدن ابعاد القيادة

دراسة تأثثر انماط مختلفة من القيادة (القيادة التبادلية مثلاً) على عمليات الانتاج الأنظف.

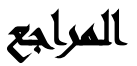

سامي بشير أبو رمان: أثز القيادة التحويلية في الاستعداد لإدارة الأزمات. المجلة الأردنية في

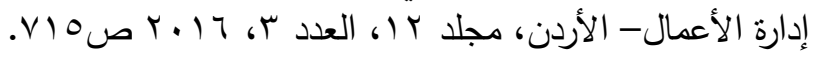

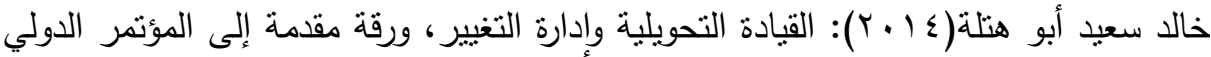

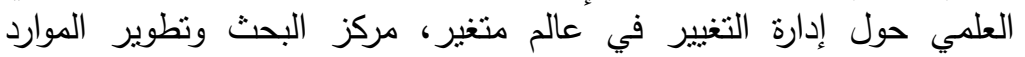

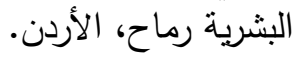

عمر على إسماعيل: إدارة الجودة البيئية الثاملة وأثره في ممارسات تكنولوجيا الإنتاج

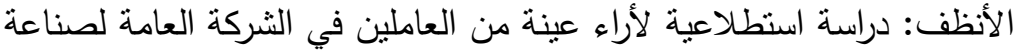

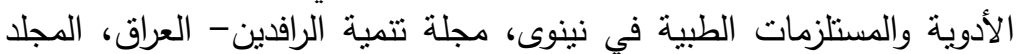

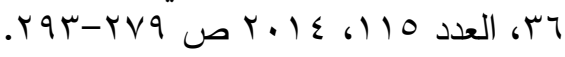

سوسن الحسيني؛ وابراهيم البلتاجي(7 ( • ب): القيادة التحويلية والابتكار : دراسة مقارنة بين

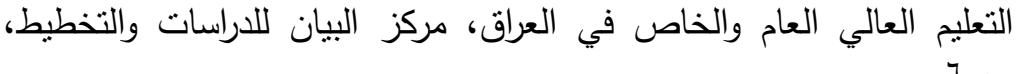

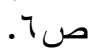

عفاف حسن هادى الساعاتي، محمود عايد حسن المساري: أثر سمات القيادة التحويلية في

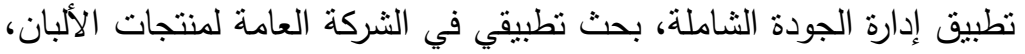

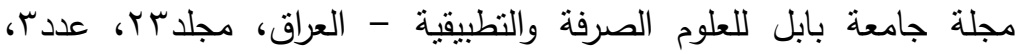

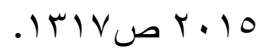

نهى عبد الرازق الثربيني: أثر القيادة التحويلية على الاستغراق الوظيفي، المجلة العلمية

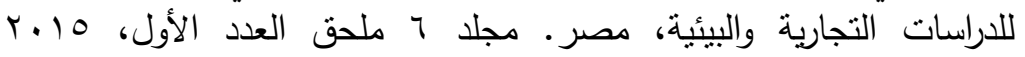

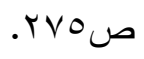

محمود عبد الرحمن إبراهيم الثنطي: دور القيادة التحويلية في عمليات إدارة المعرفة دراسة

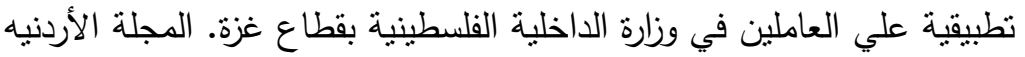

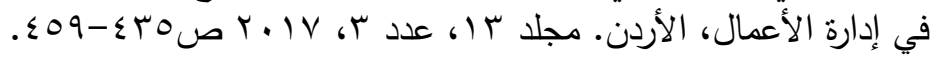

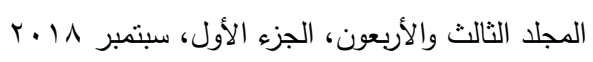


محمد غمري الثوادفى: دور القيادة التحويلية في بناء الاتجاهات نحو التغيير التتظيمي دراسة التباتية

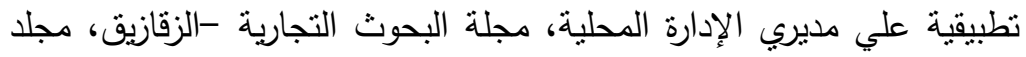

r r r العدد r)،

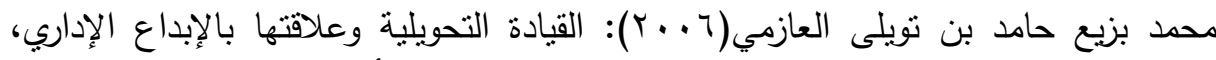

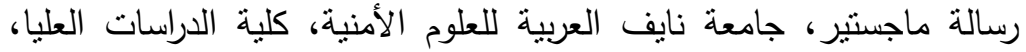

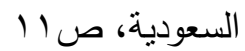

محمد عبد الوهاب العزاوي؛ أحمد سليمان محمد الجرجري: أثز القيادة التحويلية في جودة

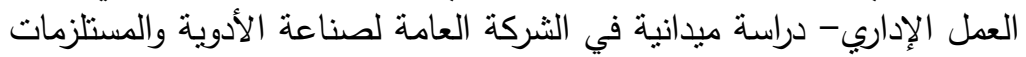

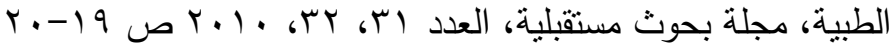

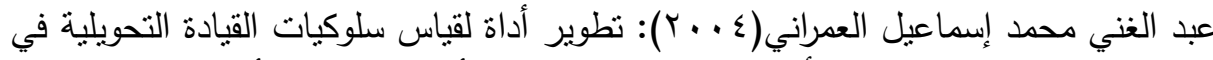

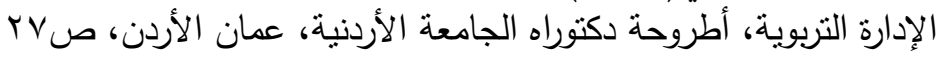

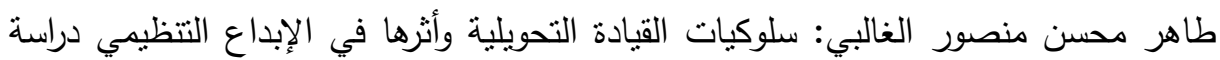

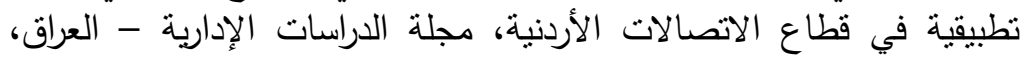

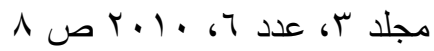

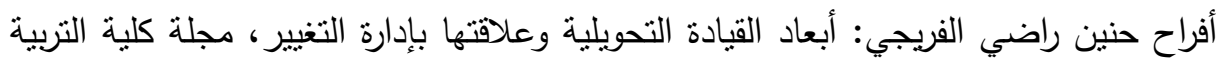

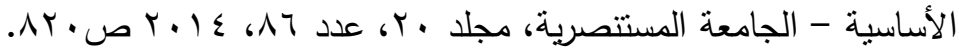

عبد المحسن النعساني: اختبار أثز أبعاد القيادة التحويلية في الإبداع الإداري- دراسة تطبية الطبيقية

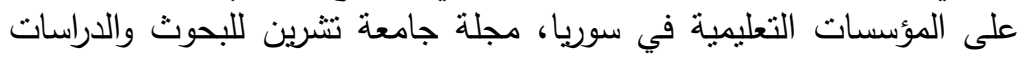

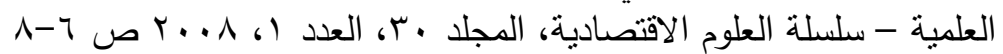

برنامج SWITCH-MED programme مشروع نقل التكنولوجيا الصديقة للبيئة في منطقة

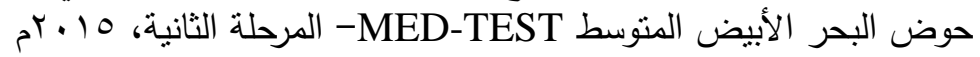

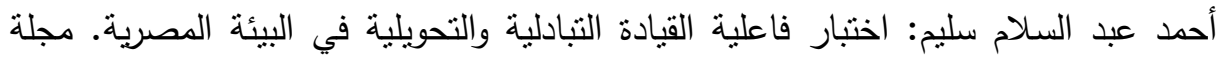

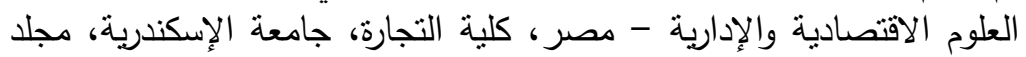

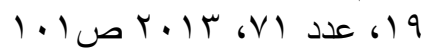

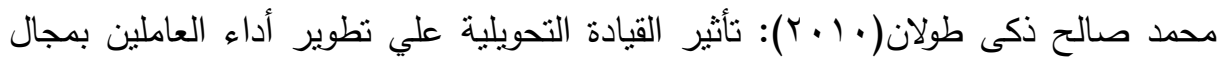

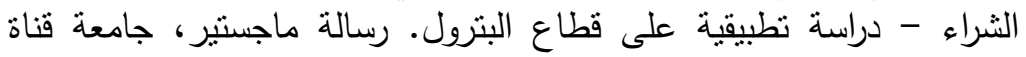

$$
\text { السويس }
$$

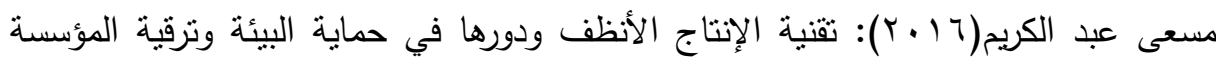

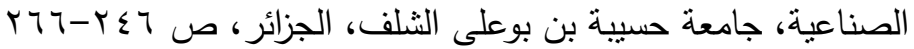




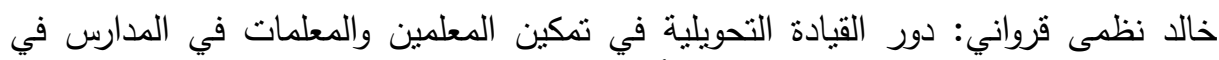

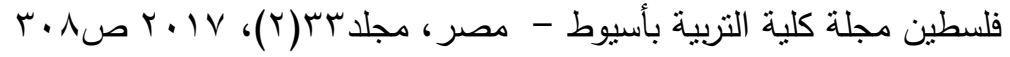

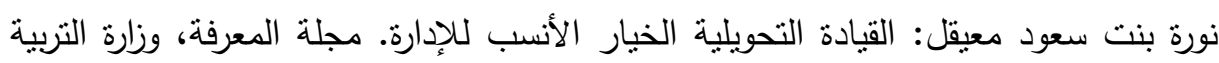

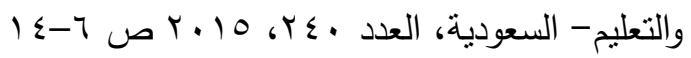

Al-Swidi, A. K.; Nawawi, M. K. and Al-Hosam, A. (2012): Is the relationship between employees' psychological empowerment and employees' job satisfaction contingent on the transformational leadership? A study on the Yemeni Islamic Banks. Asian Social Science, 8(10), 130.

Avolio, B. J. (1994): The "natural" Some antecedents to transformational leadership. International Journal of Public Administration, 17(9), 1559-1581.

Barnett, K. and McCormick, J. (2003): Vision, relationships and teacher motivation: A case study. Journal of Educational Administration, 41(1), 55-73.

Burns, J. M. (1978): Leadership. Harper and Row Publishers, New York. NY.

Chen, Y. S. and Chang, C. H. (2013): The determinants of green product development performance: Green dynamic capabilities, green transformational leadership, and green creativity. Journal of business ethics, 116(1), 107-119.

Ismail, A.; Mohamad, M. H.; Mohamed, H. A. B.; Rafiuddin, N. M. and Zhen, K. W. P. (2010): Transformational and Transactional Leadership Styles as a Predictor of Individual Outcomes. Theoretical \& Applied Economics, 17(6), 96.

Neto, A. S. and Jabbour, C. J. (2010): Guidelines for improving the adoption of cleaner production in companies through attention to non-technical factors: A literature review. African Journal of Business Management, 4(19), 42174229.

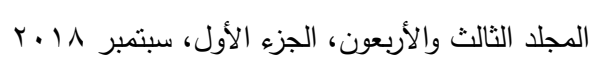


Reuvers, M.; Van Engen, M. L.; Vinkenburg, C. J. and Wilson-Evered, E. (2008): Transformational leadership and innovative work behaviour: Exploring the relevance of gender differences. Creativity and Innovation Management, 17(3), 227-244.

Sakr, D and Sena, A. A. (2017): Cleaner production status in the Middle East and North Africa region with special focus on Egypt. Journal of cleaner production, 141, 1074-1086.

Severo, E. A.; Dorion, E. C.; Olea, P. M.; Camargo, M. E.; Nodari, C. and Da Cruz, M. R. (2012): Cleaner production: cases of the metal-mechanic automotive Cluster of Serra Gaúcha. Brazil. African Journal of Business Management, 6(37), 10232.

Twigg, N. W. J. (2003): Transformational leadership, perceived union support, and union citizenship behaviors: A social exchange and social identity perspective Lucks.

Howard, J. (2002): Transformational Leadership and teacher motivation across, New York city public schools. P. 128. 
مجلة العلوم البيئية

معهد الدراسات والبحوث البيئية - جامعة عين شمس لمس لئن

\title{
THE IMPACT OF TRANSFORMATIONAL LEADERSHIP ON CLEANER PRODUCTION PROCESSES - AN APPLIED STUDY ON FOOD INDUSTRIES SECTOR
}

\author{
Abdel Hamid, Bothina, M. ${ }^{(1)}$; Refae, M. A. ${ }^{(2)}$; El-Nawawy, M. A. ${ }^{(3)}$ \\ and Sabra, M. A. ${ }^{(1)}$ \\ 1) The Higher Institute for Computer and Technology \\ Science 2) Faculty of Commerce, Ain Shams University \\ 3) Faculty of Agriculture, Ain Shams University
}

\begin{abstract}
This current study drives at testing the relationship exists between transformational leadership and processes of cleaner production; identifying as well the impact of transformational leadership dimensions on managing of cleaner production in application on food industries sector in Arab Republic of Egypt, in attempt to improve environmental performance of this sector's institutions and reinforcing the role of the transformational leader within industrial organizations. For achieving this, the research model is designed due the proposed main hypothesis of research which is based on that there is a significant statistical relationship between transformational leadership and its dimensions on one hand represented in (idealistic effect - inspiring motivation - intellectual excitement - artificial individuality developing concern in natural environment) and management of cleaner production processes on the other hand.
\end{abstract}

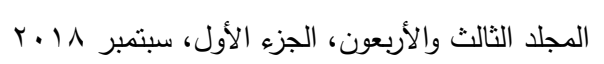


The study comes to several results including: supporting the acceptance of the research main hypothesis. The researcher comes to multiple recommendations that assist improving performance of leaders inside the sector institutions which contributes also handling and steering the cleaner production processes.

Keywords: Transformational leadership - idealistic effect - inspiring motivation - intellectual excitement - artificial individuality - cleaner production - food industries. 